\title{
Structural and optical characterizations of thin organic films of thioindigo
}

\author{
${ }^{1}$ Khusayfan N. M. and ${ }^{2}$ El-Nahass M. M. \\ ${ }^{1}$ Physics Department, Faculty of Science - AL Faisaliah Campus, King Abdulaziz \\ University, Jeddah, Saudi Arabia, e-mail:khusayfan@gmail.com \\ ${ }^{2}$ Department of Physics, Faculty of Education, Ain Shams University, Roxy 11757 , \\ Cairo, Egypt
}

Received: 09.11.2015

\begin{abstract}
We report on the structural and optical properties of the nanorods available in thermally evaporated thin films of thioindigo (TI). The structural features are investigated using X-ray diffraction, transmission electron microscopy and Fourier-transform infrared spectroscopy techniques. The optical constants of asdeposited thin TI films are determined in the wavelength region 200-2500 nm, using spectrophotometric measurements for the nearly normal light incidence. The type of optical transitions for the TI films is ascertained from the dispersion of their absorption coefficient. The real part of the refractive index in the region of optical transparency is analyzed basing on single-oscillator and Drude models. The thirdorder nonlinear susceptibility is obtained from the single-oscillator model and the Miller's rule.
\end{abstract}

Keywords: organic compound, thin films, thermal evaporation, structural and optical properties.

PACS: 78.40.Pg, 78.30.Ly, 78.20.Ci

UDC: 535.39

\section{Introduction}

Studies of the phenomena of ambipolar charge transport in organic semiconductor materials are crucial for the progress of integrated microelectronic circuits and optoelectronic devices based on organic materials. Ambipolar charge-transporting organic semiconductor materials are of great interest for many applications associated with organic light-emitting diodes [1]. Indigo is an intrinsically ambipolar organic semiconductor with the bandgap $1.7 \mathrm{eV}$, high and well-balanced electron and hole mobilities $\left(\sim 1 \times 10^{-2} \mathrm{~cm}^{2} \mathrm{~V}^{-1} \mathrm{~s}^{-1}\right)$, and a good stability with respect to degradation in air [2]. Indigo is ascribed to a group of so-called 'vat dyes', which can be reduced to compounds soluble in aqueous alkaline media. The remarkable stability of indigo and its ring-substituted derivatives has been attributed to intramolecular hydrogen bonding between the two adjacent carbonyl and $\mathrm{N}-\mathrm{H}$ groups. This keeps the molecule in a planar trans configuration, preventing a photochemical cis-to-trans isomerization [3].

It is well known that photochromic materials have great potentials for sensor and indicator devices [4]. Fig. 1 shows that the molecular structure of thioindigo (TI) can be obtained by replacing N-H groups of indigo with sulphur atoms. This substitution leads to a hypsochromic shift of the absorption wavelength maxima and allows for trans-cis isomerism. TI is a recognized photochromic dye with a reversible photochemical cis-trans isomerization $[5,6]$. The cis form typically reveals a very low, nearly immeasurable intrinsic fluorescence [7-11]. The photochromic organic materials like TI are of great interest due to their potential applications for information 
storage or switching in molecular electronics. Notice also that TI and its derivatives reveal a higher quantum-conversion yield from the cis-to-trans transition than from the trans-to-cis transition, and a concomitant high fluorescence quantum yield for the trans form.

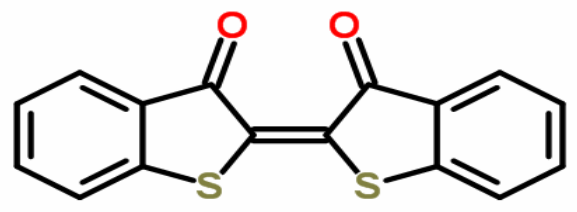

Fig. 1. Molecular structure of TI.

Early works aimed at implementing thioindigoid optical elements have been mired by overlap of the absorption bands for the cis and trans forms occurring in nearly all of thioindigoid organic dyes. As a result, even with monochromatic light incident on a sample under the condition of maximum absorption for either of the form, only photostationary states containing a mixture of the two isomers, cis and trans, could be prepared [9]. The stability of PMMA-doped TI used as a solar collector has been studied by irradiating it with a light of $1600 \mathrm{~W}$ xenon lamp through a daylight filter for $24 \mathrm{~h}$ [12]. The optical efficiency (10.7\%) has been measured before irradiation, and a slight decrease (0.052) in the efficiency has been observed after irradiation.

The optical properties of organic films, in particular thin TI films (TTIF), are significant since they are directly linked to their structural and electronic properties. Moreover, elucidation of the relations between the structure and the optical properties of thin films has both fundamental and technological impacts (see, e.g., Ref. [13]). In the present work we study the structural and optical properties of thermally evaporated TTIFs, analyze spectral dependences of their refractive index and absorption coefficient, and estimate their third-order nonlinear optical susceptibility.

\section{Experimental techniques}

TI with the chemical formula $\mathrm{C}_{16} \mathrm{H}_{8} \mathrm{O}_{2} \mathrm{~S}_{2}$ was obtained from Sigma-Aldrich Chem. Co. TTIFs were deposited using a high-vacuum coating unit "Edward E306A, England" under the vacuum of $4 \times 10^{-5} \mathrm{~Pa}$. The films were deposited on optically flat fused quartz substrates for further spectrophotometric measurements and on glass substrates for structural characterizations. Sublimation of TI was done using a quartz crucible heated by a tungsten coil. The sublimation rate $(2.5 \mathrm{~nm} / \mathrm{sec})$ and the film thickness were controlled with a quartz crystal monitor FTM6. The film thicknesses were determined after deposition, using multiple-beam Fizeau fringes in the reflection geometry [14]. X-ray diffraction patterns were studied with a Philips X-ray diffractometer (a model X' Pert, $\mathrm{CuK}_{\alpha}$ radiation, $1.5406 \AA, 40 \mathrm{kV}$, and $25 \mathrm{~mA}$ ). Crystallite shapes of our TTIFs were determined on a transmission electron microscope JEOL JEM-1230. TTIFs deposited on glass substrates were immersed in an inclined manner in a glass dish containing a mixture of distilled water and one or two drops of a concentrated nitric acid. The TTIFs floating on the surface of the solution were fished by copper-coated carbon grid and left to dry before the measurements.

In the far infrared range, the spectra for the TI powders mixed with $\mathrm{KBr}$ and the $\mathrm{TI}$ films deposited onto optically flat single-crystalline substrates of $\mathrm{KBr}$ were investigated in the region $500-4000 \mathrm{~cm}^{-1}$, using an infrared spectrophotometer Bruker Vector 22. In this case the spectral resolution was $\pm 1 \mathrm{~cm}^{-1}$ throughout the experiments. In the ultraviolet, visible and near infrared spectral ranges, optical characterizations of the deposited films were performed at the nearly normal light incidence in the wavelength region $200-2500 \mathrm{~nm}$, using a double-beam 
spectrophotometer JASCO (the model V-570 UV-Vis-NIR). We transformed the relative spectral data of the optical transmittance $T$ and the reflectance $R$ obtained directly from the spectrophotometer into the corresponding absolute values $T$ and $R$ by making corrections to eliminate the absorbance and reflectance of the substrate. Then the absolute $T$ value is given by [15-17]

$$
T=\left(\frac{I_{f t}}{I_{q}}\right)\left(1-R_{q}\right),
$$

where $I_{f t}$ and $I_{q}$ denote the intensities of light passed respectively through the film-quartz system and the reference quartz, and $R_{q}$ is the reflectance of the quartz substrate. The true reflectance $R$ reads as $[15-17]$

$$
R=\left(\frac{I_{f r}}{I_{m}}\right) R_{m}\left(1+\left[1-R_{q}\right]^{2}\right)-T^{2} R_{q}
$$

where $I_{m}$ implies the intensity of light reflected from the reference mirror, $I_{f r}$ the intensity of light reflected from the sample and $R_{m}$ the mirror reflectance. Assuming a case of smooth, dense and homogeneous films, we derived their optical constants as [18, 19]

$$
\begin{aligned}
& \alpha=\frac{1}{d} \ln \left[\frac{(1-R)^{2}}{2 T}+\sqrt{\frac{(1-R)^{4}}{4 T^{2}}+R^{2}}\right], \\
& k=\frac{\alpha \lambda}{4 \pi}, \\
& n=\left(\frac{1+R}{1-R}\right)+\sqrt{\frac{4 R}{(1-R)^{2}}-k^{2}},
\end{aligned}
$$

where $\alpha$ is the absorption coefficient, $k$ the absorption index, $n$ the refractive index, and $d$ the film thickness. The resultant errors for the $n$ and $k$ parameters were less than $\pm 4 \%$ (see Ref. [20]), whereas the errors in determination of the film thickness and the $T$ (or $R$ ) parameter were estimated as $\pm 2 \%$ and $\pm 1 \%$, respectively.

\section{Results and discussion}

Fig. 2 displays the X-ray diffraction patterns obtained for TI in its powder form and for the $179 \mathrm{~nm}$-thick TTIF. The diffraction pattern of the powder involves several peaks of different intensities, thus testifying that the powder is polycrystalline in its nature. The Crysfire\&Checkcell computing programs $[21,22]$ have been used to index all the diffraction lines, calculate the Miller indices $(h k l)$ and the interplanar spacing $\left(d_{h k l}\right)$ for each diffraction peak and, finally, calculate the lattice parameters. The analysis has demonstrated that the TI powder has a monoclinic structure and crystallizes in the space group $P c$. The lattice constants are $a=7.735 \AA, b=20.585 \AA$ and $c=7.411 \AA$, and the monoclinic angle equals to $\beta=90.26^{\circ}$. The structural experiments for the deposited TTIF of the thickness mentioned above have confirmed a crystalline structure, with a preferred orientation along the (020) plane.

The transmission electron microscopy technique has been used to analyze crystallographic structure and orientation of the constituents of the TTIFs. From the transmission-electron 
micrograph of our TTIF (see Fig. 3a) one concludes that the film reveals a uniform distribution of nanoparticles with rod-like shapes. These rods have the average length $90 \mathrm{~nm}$ and the average width $20 \mathrm{~nm}$. Fig. $3 \mathrm{~b}$ displays the electron-diffraction pattern for the same TTIF. This pattern consists of a series of sharp concentric rings, which have to be ascribed essentially to a crystalline nature of the film, in accordance with the X-ray diffraction data.

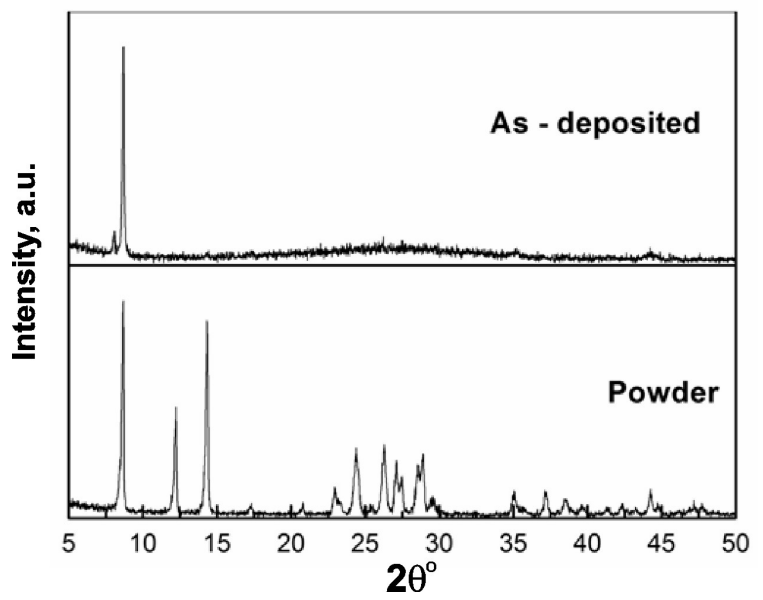

Fig. 2. X-ray diffraction patterns obtained for $\mathrm{TI}$ in its powder and thin-film forms.

Fig. 4 shows profiles of the Fourier-transform infrared spectra obtained for both the powder and thin-film forms of TI in the region $500-4000 \mathrm{~cm}^{-1}$. The shape of the spectrum for the TTIF implies availability of characteristic bonds, which also appear in the powder. In other words, thermal evaporation represents an adequate technique that provides deposition of undissociated and stoichiometric TI films. Note that the spectral bands observed for TI molecules in the Fouriertransform infrared spectra have already been discussed and assigned by Ibrahim et al. [5].
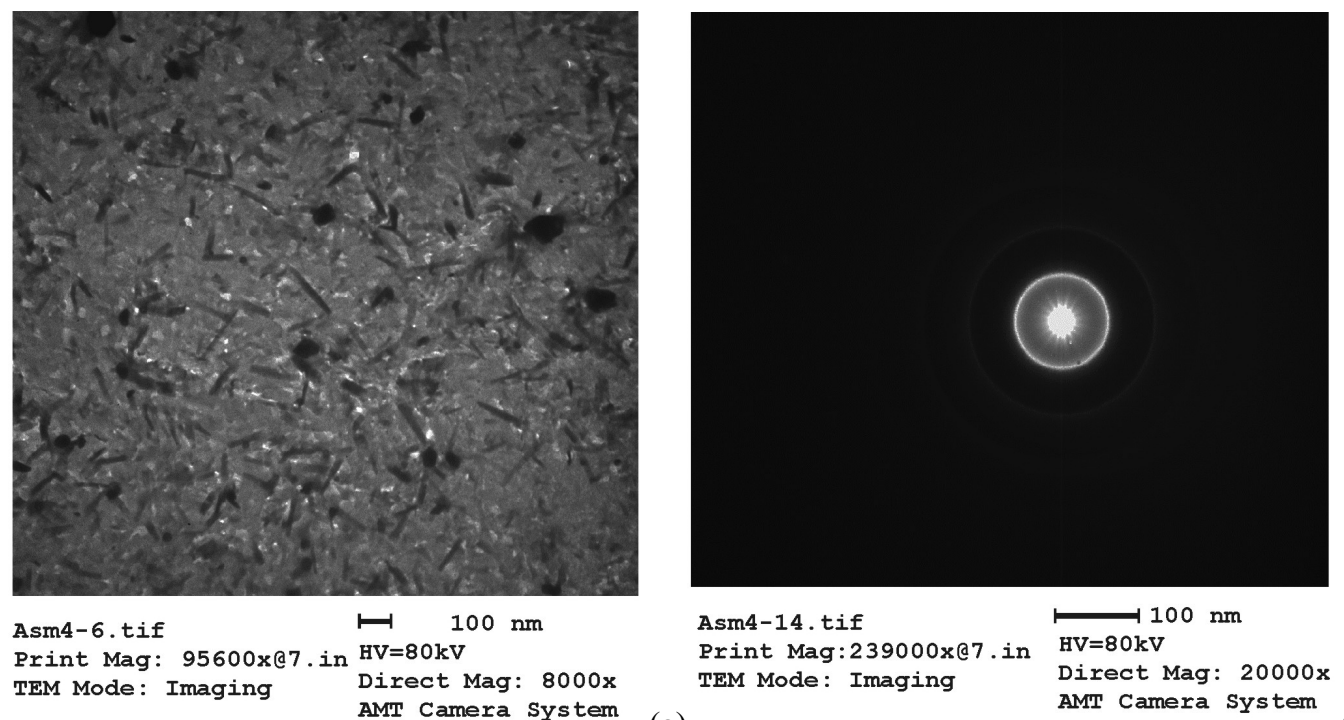

(a)

(b)

Fig. 3. Transmission-electron micrograph (a) and diffraction electron microscope pattern (b) obtained for the TTIF.

Ukr. J. Phys. Opt. 2016, Volume 17, Issue 1 


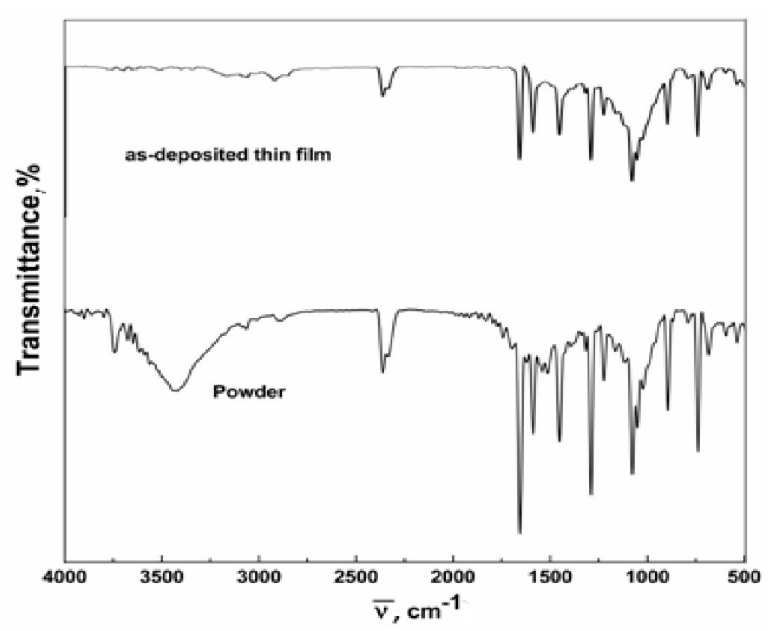

Fig. 4. Fourier-transform infrared spectra for $\mathrm{TI}$ in its powder and thin-film forms.

The spectral dependences $T(\lambda)$ and $R(\lambda)$ for the TTIFs of different thicknesses ranging from 227 to $285 \mathrm{~nm}$ are illustrated in Fig. 5. The spectra can be divided into two alternative regions: (i) the absorption region, $200-800 \mathrm{~nm}$, where the total sum of $T(\lambda)$ and $R(\lambda)$ is essentially less than unity, and (ii) the longer-wavelength region, $800-2500 \mathrm{~nm}$, where the films become transparent, so that we have $T+R \sim 1$. The fundamental edge in the absorption region (i) remains almost unchanged by varying film thickness, at least in the thickness range under study. Perhaps, the data of Fig. 5 imply that the thickness variations are too small to result in detectable changes in the $T$ and $R$ parameters. The $T(\lambda)$ and $R(\lambda)$ functions in the transparency region (ii) are also very similar for all of the films.

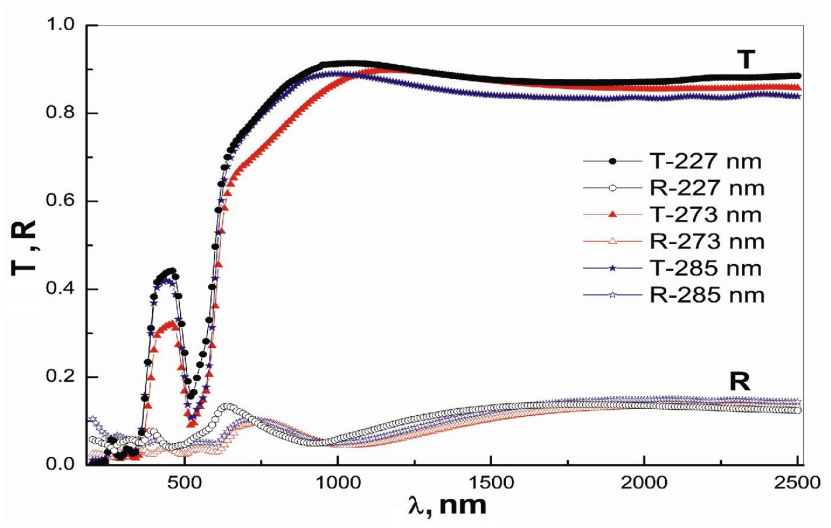

Fig. 5. Spectral dependences of optical transmittance $T$ and reflectance $R$ calculated for TTIFs of different thicknesses shown in the legend.

Following from the absolute $T$ and $R$ values, we have calculated the optical constants $n$ and $k$ of the TTIF. Panels (a) and (b) in Fig. 6 show the spectral dependences respectively of the mean real part of the refractive index, $n$, and of the mean absorption coefficient, $\alpha$. Considering the experimental errors estimated above, we conclude that both of the $n$ and $k$ values are independent of the film thickness, at least in the thickness range under test. The real part of the refractive index exhibits anomalous dispersion in the photon energy region $1.55-6.20 \mathrm{eV}(200-800 \mathrm{~nm})$ and normal dispersion in the region $0.50-1.55 \mathrm{eV}(800-2500 \mathrm{~nm})$. 

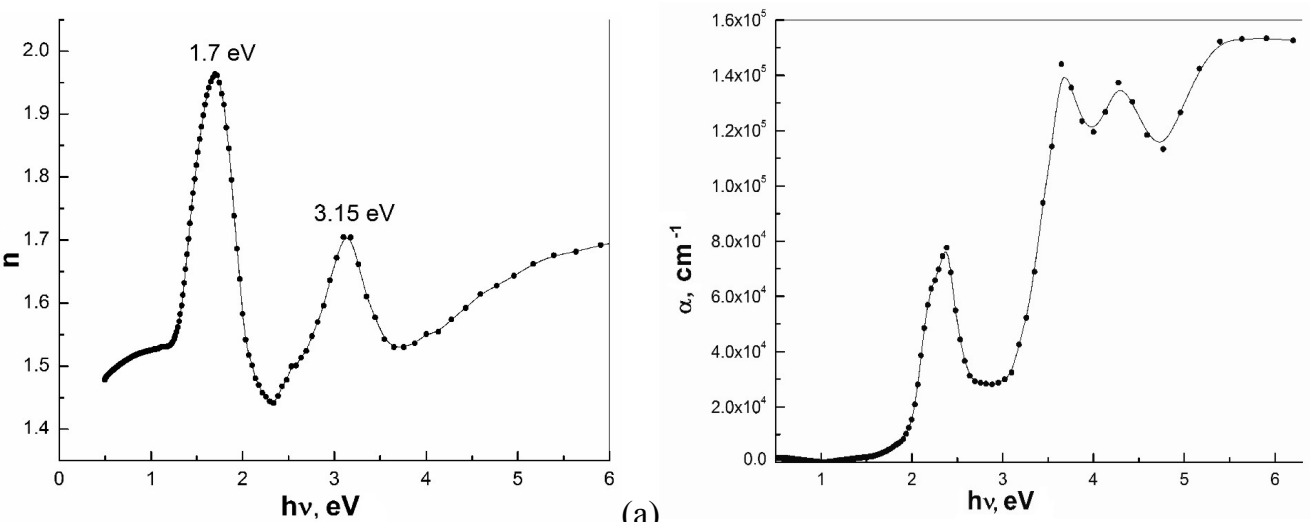

(b)

Fig. 6. Dependences of real part of the mean refractive index $n$ (a) and mean absorption coefficient $\alpha$ (b) upon the photon energy $h v$, as calculated for our TTIF.

Following from the absorption coefficient, one can obtain the molar extinction coefficient $\varepsilon_{\text {molar }}$, which is often used to describe optical absorption in non-solid molecular media. Then we have calculated the oscillator strengths $f$, which are proportional to the area under the absorption band profiles, and the electric dipole strength $q^{2}$ [23-25]:

$$
\begin{aligned}
& \alpha(h v)=2.303 \times 10^{3}\left(\frac{\rho}{M}\right) \times \varepsilon_{\text {molar }}, \\
& f=4.3 \times 10^{-9} \int \varepsilon_{\text {molar }}(\bar{v}) d \bar{v} \\
& q^{2}=\frac{1}{2500} \varepsilon_{\text {molar }}(\bar{v})\left(\frac{\Delta \lambda}{\lambda}\right)
\end{aligned}
$$

Here $M$ denotes the molecular weight of a solid, $\rho$ its mass density, $\varepsilon_{\text {molar }}(\bar{v})$ the molar extinction coefficient corresponding to the wave number $\bar{v}\left(\mathrm{~cm}^{-1}\right)$, and $\Delta \lambda$ the halfwidth of the absorption band. Fig. 7 shows $\varepsilon_{\text {molar }}$ for our TTIF as a function of the wave number $\bar{v}$. When deriving the oscillator strength and the electric dipole strength, we have assumed four different oscillator components and their Gaussian profiles (see Table 1). The blue solid curves in Fig. 7 represent decomposition of the molar extinction spectrum on the relevant oscillator components.

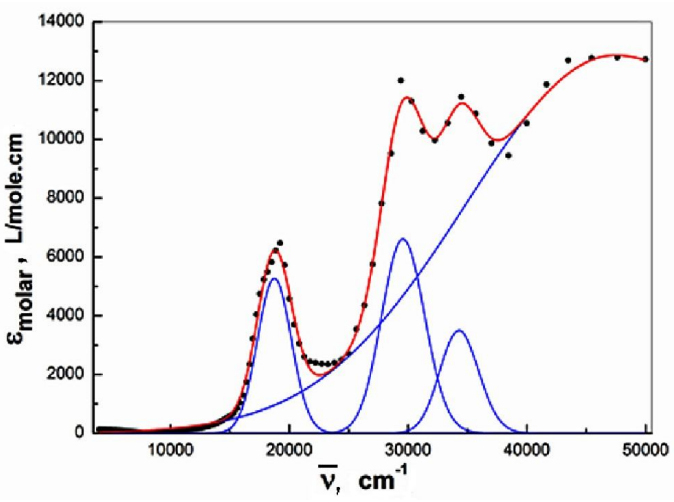

Fig. 7. Dependence of molar extinction coefficient on the wave number obtained experimentally for the asdeposited TTIF (black circles) and its theoretical fit (red solid line) that assumes four oscillator components with Gaussian profiles. Blue lines correspond to decomposition of the spectrum into these Gaussian components.

Ukr. J. Phys. Opt. 2016, Volume 17, Issue 1 
Table 1. Spectral positions $E_{\max }$, oscillator strengths $f$ and electric dipole strengths $q^{2}$ calculated for the four Gaussian peaks, as obtained for our as-deposited TTIF (see Fig. 7 and explanations in the text).

\begin{tabular}{|c|c|c|c|}
\hline Peak & $E_{\max }, \mathrm{cm}^{-1}$ & $f$ & $q^{2}, \AA^{2}$ \\
\hline 1 & 18742 & 0.08 & 0.320 \\
\hline 2 & 29540 & 0.13 & 0.322 \\
\hline 3 & 34303 & 0.62 & 0.133 \\
\hline 4 & 47626 & 1.77 & 2.745 \\
\hline
\end{tabular}

The nature of optical transitions and the corresponding bandgap can be estimated using the Tauc's equation given by [26]

$$
\alpha h v=B\left(h v-E_{g}\right)^{r},
$$

where $B$ and $r$ are constants depending on the probability of transition: $r$ takes the values $r=1 / 2$ and $3 / 2$ respectively for the direct allowed and direct forbidden transitions, and $r=2$ and 3 respectively for the indirect allowed and indirect forbidden transitions. We have plotted the dependence of $(\alpha h v)^{1 / r}$ on the photon energy $h v$ for different $r$ values. The best linear fit is obtained at $r=2$ (see Fig. 8). This implies that we deal with the indirect allowed optical transitions. One can indirectly estimate the indirect optical bandgap for our TTIF after extrapolating the straight fitting line in the plot of $(\alpha h v)^{1 / 2}$ vs. $h v$ towards the abscissa axis $\left((\alpha h v)^{1 / 2}=0\right)$. It has turned out that the as-deposited TTIF has two transitions at $1.54 \mathrm{eV}$ and $2.24 \mathrm{eV}$, which should correspond to the optical gap energy $E_{g}^{\text {opt }}$ and the fundamental bandgap $E_{g}$, respectively.

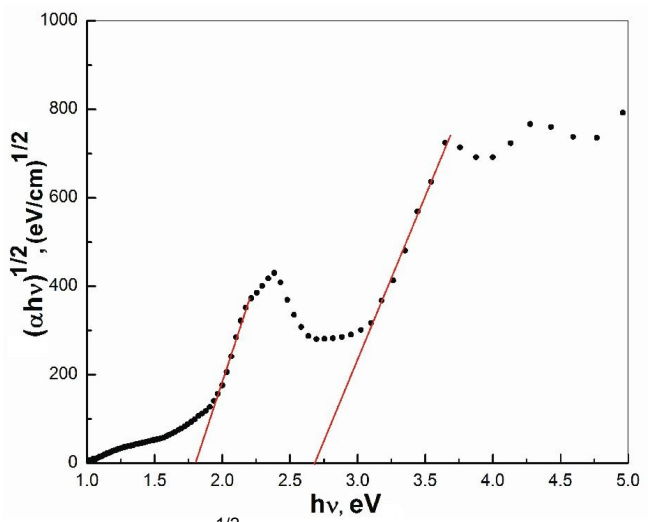

Fig. 8. Relation between $(\alpha h v)^{1 / 2}$ and photon energy $h v$ calculated for our TTIF.

According to the classical dispersion theory, the photon-energy dependence of the real part of the refractive index in the transparency region, where oscillator damping is negligible, is given by a single-oscillator model [27-29]:

$$
\frac{1}{n^{2}-1}=\frac{E_{0}}{E_{d}}-\frac{1}{E_{o} E_{d}}(h v)^{2}
$$

where $E_{o}$ implies the oscillator energy and $E_{d}$ the dispersion energy which is a measure of the strength of interband optical transitions [28]. The dispersion parameters and the static dielectric constant $\left(\varepsilon_{\infty}=n^{2}\right.$ at $\left.h v \rightarrow 0\right)$ for our as-deposited TTIF can be calculated by plotting $\left(n^{2}-1\right)^{-1}$ versus $(h v)^{2}$, as displayed in Fig. 9a. Then the $E_{o}$ and $E_{d}$ values are found from the slope $\left(E_{o} E_{d}\right)^{-1}$ and from the intercept $\left(E_{o} / E_{d}\right)$ with the ordinate axis. The $\varepsilon_{\infty}, E_{d}$ and $E_{o}$ values are equal to $2.26,5.8$ and $4.6 \mathrm{eV}$, respectively. 

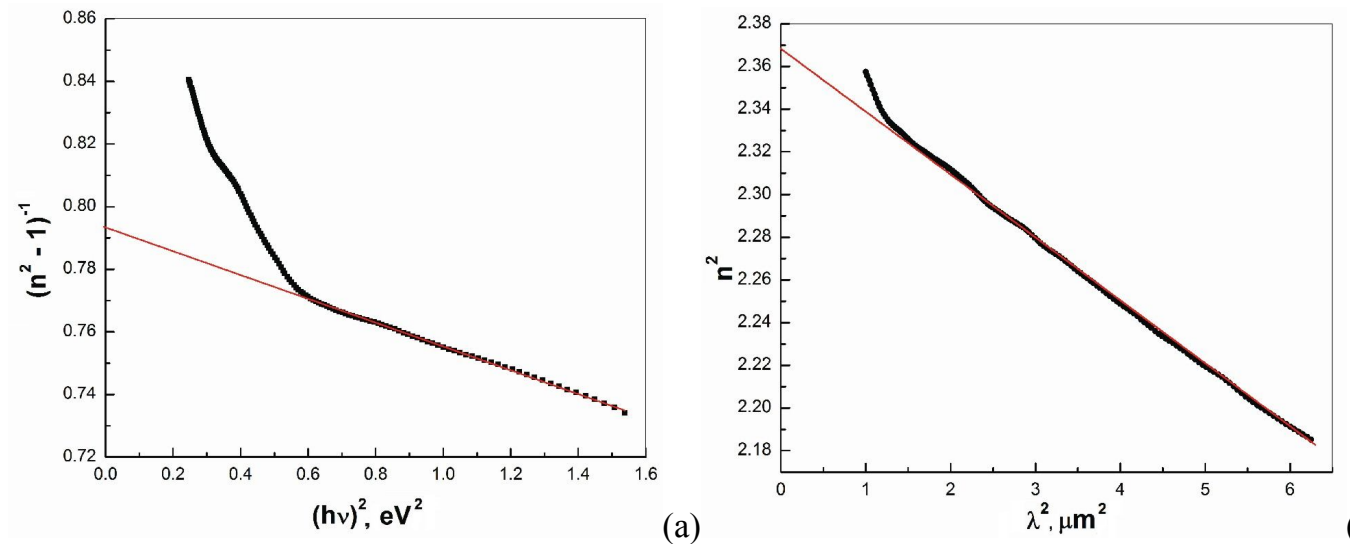

(b)

Fig. 9. Relations between $\left(n^{2}-1\right)^{-1}$ and $(h v)^{2}$ (a) and between $n^{2}$ and $\lambda^{2}(\mathrm{~b})$, as calculated for our TTIF.

Finally, the generalized Miller's rule [30-32],

$$
\chi^{(3)}=\frac{A}{(4 \pi)^{4}}\left(n_{o}^{2}-1\right)^{4}=\frac{A}{(4 \pi)^{4}}\left(\frac{E_{d}}{E_{o}}\right)^{4},
$$

enables one to estimate the third-order nonlinear susceptibility $\chi^{(3)}$ in the limit of very long wavelengths (i.e., at $h v \rightarrow 0$ when the refractive index is equal to $n_{o}$ ). In Eq. (11), $A$ denotes a parameter which is assumed to be frequency independent and nearly the same for all materials $\left(A \approx 1.7 \times 10^{-10}\right.$ esu [30-32]). Issuing from our experimental data, we have obtained $\chi^{(3)} \approx 1.73 \times 10^{-14} \mathrm{esu}$.

According to the Drude model for the absorption of free charge carriers, which takes into account the contributions of free carriers and lattice vibration modes to the dispersion, the spectral dependence of $n^{2}$ on $\lambda^{2}$ can be used to estimate the lattice dielectric constant $\varepsilon_{L}$. The relationship between the real dielectric constant $\varepsilon_{1}$ and $\lambda^{2}$ in the optical transparency region is as follows [33]:

$$
\varepsilon_{1}=n^{2}=\varepsilon_{L}-\frac{e^{2} N}{4 \pi^{2} \varepsilon_{o} m^{*} c^{2}} \lambda^{2},
$$

where $e$ is the electron charge, $\varepsilon_{o}$ the permittivity of free space, and $N / m^{*}$ the ratio of the concentration of free carriers to their effective mass. Fig. $9 \mathrm{~b}$ shows the plot $n^{2}$ versus $\lambda^{2}$ calculated for the TTIF. This dependence is linear at long enough wavelengths. Extrapolating the linear part of the dependence towards 'zero wavelength' gives the $\varepsilon_{L}$ value, whereas the slope of this part yields $N / m^{*}$. As a result, we have obtained $\varepsilon_{L} \approx 2.37$ and $N / m^{*} \approx 3.772 \times 10^{55} \mathrm{~kg}^{-1} \mathrm{~m}^{-3}$. Notice that the difference between the $\varepsilon_{L}$ value derived from the Drude model for the absorption of free carriers and the $\varepsilon_{\infty}$ value derived from the single-oscillator model for bounded charges may be due to contribution of free carriers.

\section{Conclusions}

We have performed structural and optical characterizations of the nanorods available in thermally evaporated TTIFs. The Fourier-transform infrared spectra for the TI powder and the TTIF confirm that the chemical composition of TI does not change after the thermal evaporation technique is applied. The crystal structure studies carried out for the TI powder and the corresponding thin films using the X-ray technique indicated that the both systems crystallize in the monoclinic 
system. According to the transmission electron microscopy data, the nanorods have the average length of $90 \mathrm{~nm}$ and the average width of $20 \mathrm{~nm}$.

We have used the Tauc's equation for the analysis of optical transitions occurring in the TI nanorods and found that there are two indirect transitions with the energies 1.54 and $2.24 \mathrm{eV}$, which correspond to the optical gap and the fundamental bandgap, respectively. The classical single-oscillator model and the Drude model for the absorption of free carriers have been used while analyzing the refractive dispersion in its normal region. Using the single-oscillator model, we have derived the third-order nonlinear susceptibility, which is equal to $1.73 \times 10^{-14}$ esu, and the closely related model parameters, the oscillator energy $E_{o}=4.6 \mathrm{eV}$ and the dispersion energy $E_{d}=5.8 \mathrm{eV}$. Finally, we have calculated the ratio of the concentration of free carriers to their effective mass, which amounts to $3.772 \times 10^{55} \mathrm{~kg}^{-1} \mathrm{~m}^{-3}$.

\section{Acknowledgement}

The present study was funded by the Deanship of Scientific Research (DSR), King Abdulaziz University, Jeddah, under the Grant No. 72/363/1434. The authors also acknowledge a technical support from the DSR.

\section{References}

1. Gudeika D, Grazulevicius J, Sini G, Bucinskas A, Jankauskas V, Miasojedovas A and Jursenas S, 2014. New derivatives of triphenylamine and naphthalimide as ambipolar organic semiconductors: Exper. and Theor. Approach. Dyes and Pigments. 106: 58-70.

2. Irimia-Vladu M, Głowacki E D, Troshin P A, Schwabegger G, Leonat L, Susarova D K, Krystal O, Ullah M, Kanbur Y, Bodea M A, Razumov V F, Sitter H, Bauer S and Sariciftci N $\mathrm{S}, 2012$. A natural pigment for high performance ambipolar organic field effect transistors and circuits. Adv. Mater. 24: 375-380.

3. Seixas de Melo J, Moura A P and Melo M J, 2004. Photophysical and spectroscopic studies of indigo derivatives in their keto and leuco forms. J. Phys. Chem. A. 108: 6975-6981.

4. Bamfield P and Hutchings M G. Chromic phenomena: Technological applications of colour chemistry, $2^{\text {nd }}$ Ed. Royal Society of Chemistry (2010).

5. Ibrahim M, El-Nahass M M, Kamel M A, El-Barbary A A, Wagner B D and El-Mansy M A M, 2013. On the spectroscopic analyses of thioindigo dye. Spectrochim. Acta A. 113: 332336.

6. Schulz M and Christoffers J, 2013. New macrocyclic bistriazolophanes with thioindigo chromophore. Tetrahedron. 69: 802-809.

7. Petersen J, Strohmaier R, Gompf B and Eisenmenger W, 1997. Monolayers of tetrachlorothioindigo and thioindigo in the STM: orientational disorder and the absence of photochromism. Surf. Sci. 389: 329-337.

8. Cherepy N J and Sanner R D, 2006. Synthesis and optical properties of photochromic perinaphthothioindigo. Opt. Mater. 28: 1350-1354.

9. Eltsov A V, Ed. Organic photochromes. New York: Plenum Publishing Corporation (1990).

10. Blanc $\mathrm{J}$ and Ross D L, 1968. Procedure for determining the absorption spectra of mixed photochromic isomers not requiring their separation. J. Phys. Chem. 72: 2817-2824.

11. Wyman G M and Zarnegar BM, 1973. Excited state chemistry of indigoid dyes. I. Fluorescence versus cis-trans isomerization. J. Phys. Chem. 77: 831-837.

12. Abdel Rahman A N and Mansour A F, 1985. Trans-thioindigo as a possible dye for solar collectors. J. Phys. D. 18: L49-L52. 
13. Gao L, Lemarchand F and Lequime M, 2012. Exploitation of multiple incidences spectrometric measurements for thin film reverse engineering. Opt. Express. 20: 1573415751.

14. Tolansky S. Multiple beam interferometry of surfaces and films. London: Oxford University (1948)

15. El-Nahass M M and Hassanien A M, 2014. Gamma radiation-induced changes on the optical properties of dibenzthiopheno-perylene-N, $\mathrm{N}^{\prime}$-dicyclohexylimide thin films. Radiat. Phys. Chem. 97: 178-183.

16. El-Nahass M M, Afify H A, Gadallah A-S, Hassanien A M and AttaKhedr M, 2014. Effect of thermal annealing on structural and optical properties of titanyl phthalocyanine thin films. Mater. Sci. Semicond. Proc. 27: 254-260.

17. El-Nahass M M, Farag A A M and El-Sayed H E A, 2003. Structural and optical characterization of polycrystalline $\mathrm{CdSe}_{\mathrm{x}} \mathrm{Te}_{1-\mathrm{x}}$ thin films. Appl. Phys. A. 77: 819-826.

18. Di Giulio M, Micocci G, Rella R, Siciliano P and Tepore A, 1993. Optical absorption of tellurium suboxide thin films. Phys. Stat. Solidi (a). 136: K101-K104.

19. El-Nahass M M, Hassanien A M, Abu-Samaha F S H and Elesh E, 2014. Effect of illumination on the structural and optical properties of $\mathrm{Cu}$ (II) tetraphenyl porphyrin (CuTPP) thin films. Opt. Commun. 325: 116-121.

20. Konstantinov I, Babeva T and Kitova S, 1998. Analysis of errors in thin-film optical parameters derived from spectrophotometric measurements at normal light incidence. Appl. Opt. 37: 4260-4267.

21. Shirley R. The CRYSFIRE system for automatic powder indexing: User's manual. Guildford: The Lattice Press (2000).

22. Laugier J and Bochu B, LMGP-suite of programs for the interpretation of X-ray experiments. ENSP/Laboratoire des Matériaux et du Génie Physique (Saint-MartindHères, France, 2000).

23. Kumar G A, Thomas J, George N, Kumar B A, Shnan P R, Poori V P N, Vallabhan C P G and Unnikrishnan N V, 2000. Optical absorption studies of free $\left(\mathrm{H}_{2} \mathrm{Pc}\right)$ and rare earth $(\mathrm{RePc})$ phthalocyanine doped borate glasses. Phys. Chem. Glass. Europ. J. Glass Sc. Tech. B 41: 8993.

24. Gouterman M, 1959. Study of the effects of substitution on the absorption spectra of porphin. J. Chem. Phys. 30: 1139-1161.

25. El-Nahass M M, Hassanien A M and Khusayfan N M, 2013. Optical characterizations of thermally evaporated perylene-66 (dye content 40\%) thin films. Solid State Commun. 154: 51-55.

26. Pal U, Samanta D, Ghori S and Chaudhuri A K, 1993. Optical constants of vacuumevaporated polycrystalline cadmium selenide thin films. J. Appl. Phys. 74: 6368-6374.

27. Wemple S H and DiDomenico Jr M, 1971. Behavior of the electronic dielectric constant in covalent and ionic materials. Phys. Rev. B. 3: 1338-1351.

28. Wemple S H, 1973. Refractive-index behavior of amorphous semiconductors and glasses. Phys. Rev. B. 7: 3767-3777.

29. El-Nahass M M, El-Deeb A F, Metwally H S and Hassanien A M, 2010. Structural and optical properties of iron (III) chloride tetraphenylporphyrin thin films. Eur. Phys. J. Appl. Phys. 52: 10403-10411.

30. Miller R C, 1964. Optical second harmonic generation in piezoelectric crystals. Appl. Phys. Lett. 5: 17-19. 
31. Wang C C, 1970. Empirical relation between the linear and the third-order nonlinear optical susceptibilities. Phys. Rev. B. 2: 2045-2048.

32. Tichý L, Tichá Hx, Nagels P, Callaerts R, Mertens R and Vlček M, 1999. Optical properties of amorphous As-Se and Ge-As-Se thin films. Mater. Lett. 39: 122-128.

33. Palik E D. Handbook of optical constants of solids. New York: Academic Press (1985).

Khusayfan N. M. and El-Nahass M. M. 2016. Structural and optical characterizations of thin organic films of thioindigo. Ukr.J.Phys.Opt. 17: $10-20$.

Анотація. В цій роботі представлені результати досліджень структурних і оптичних властивостей нано-стержнів присутніх в тонких плівках тіоіндиго (ТI) виготовлених термічним випаровуванням. Структурні характеристики досліджені з використанням Xпроменевої дифракиії, трансмісійної електронної спектроскопї $i$ інфррачервоної Фур'є спектроскопії. Визначені оптичні константи нанесених плівок TI в області довжин хвиль 200-2500 нм за допомогою спектрофотометричних вимірювань при майже нормальному падінні випромінювання. Встановлено тип оптичних переходів на основі дисперсії коефіціснта поглинання. Проаналізована дисперсія дійсної частини показника заломлення 6 області прозорості на основі одно-осииляторної моделі Друде. Коефічієнт кубічної нелінійної сприйнятливості отримано на основі одно-осииляторної моделі $i$ правила Міллера. 